Susan E. Coldwell, PhD

Julie A. Mennella, PhD

Valerie B. Duffy, PhD

Marcia L. Pelchat, PhD

James W. Griffith, PhD

Gregory Smutzer, PhD

Beverly J. Cowart, $\mathrm{PhD}$

Paul A.S. Breslin, PhD

Linda M. Bartoshuk, PhD

Lloyd Hastings, PhD

David Victorson, PhD

Howard J. Hoffman, MA

Correspondence to

Dr. Coldwell:

scoldwel@u.washington.edu

\title{
Gustation assessment using the NIH Toolbox
}

\section{ABSTRACT}

The NIH Toolbox for Assessment of Neurological and Behavioral Function (NIH Toolbox) is a set of brief measures for the assessment of cognitive function, emotional health, motor function, and sensory function for use in clinical trials and in epidemiologic and longitudinal studies. Gustatory perception is assessed as 1 of 6 areas of sensory function. A team of 11 scientists with expertise in taste perception selected 2 gustatory measures, 1 of which can be used in young pediatric populations. The measure selected for young pediatric populations assesses sucrose (sweet) taste preference and can also be used across the age span of 5 to 85 years. For adult populations, the selected measure is a regional test, which assesses variability in perceived intensity of quinine hydrochloride (bitter) when applied to the tongue tip as well as perceived with the whole mouth. The team also recommends the regional test for assessing other tastants, such as sodium chloride (salty). Validation studies have demonstrated that the measures modified for the NIH Toolbox correlate with more traditional assessments, and can identify known population differences in gustation. Neurology ${ }^{\circledR}$ 2013;80 (Suppl 3):S20-S24

DEFINITION OF GUSTATION Gustation consists of the perception of sensations that are usually described as having 1 or more basic taste qualities: sweet, salty, sour, bitter, or umami (savory/brothy). These sensations facilitate consumption of nutrients (sweet, salty, umami) and contribute to rejection of toxins (bitter). The gustatory system's key function in guiding food intake makes it important to health and the prevention of chronic diseases and conditions. For example, individual differences in bitter taste perception are known to contribute to differences in food preferences and consumption of certain fruits and vegetables, thereby influencing health. ${ }^{1}$ Gustation arises from the cellular activation of taste receptors that are localized to the plasma membranes of modified epithelial cells. ${ }^{2}$ Along with supporting cells, these specialized cells form taste buds that are found inside papillae on the tongue surface or within the tissues of the soft palate and pharynx. Gustatory fibers in the facial, glossopharyngeal, and vagal cranial nerves innervate taste buds in the oral cavity. These fibers carry taste information from the oral cavity to the nucleus of the solitary tract in the brainstem. ${ }^{3}$ In primates, projections from the nucleus of the solitary tract carry taste information to the thalamus, which in turn projects to gustatory cortex. ${ }^{3}$

Psychophysical measures characterize different aspects of gustatory perception. These include the responsiveness of the system to taste stimuli as well as the hedonic value of the sensation. Measures of taste function include detection thresholds, just noticeable differences in taste perception, perceived intensity, and taste quality judgments. Measurements involving hedonic value usually consist of estimates of pleasantness, liking, or preference. For children younger than age 5, most psychophysical measures assess hedonic value of taste by acceptance or rejection of foods or simple taste solutions.

NIH TOOLBOX FOR ASSESSMENT OF NEUROLOGICAL AND BEHAVIORAL FUNCTION: METHODOLOGY SELECTED FOR NIH TOOLBOX GUSTATION ASSESSMENTS The Taste Team comprised scientists with expertise in human taste perception augmented by experts in experimental psychology, epidemiology, public health, and statistics. This team engaged in a series of discussions that led to the selection of gustatory measures for the NIH Toolbox for Assessment of Neurological and Behavioral Function (NIH Toolbox). Scientists with knowledge of both pediatric and geriatric taste perception participated. At the outset, the team was instructed

From the University of Washington (S.E.C.), School of Dentistry, Seattle, WA; Monell Chemical Senses Center (J.A.M., M.L.P., B.J.C., P.A.S.B.), Philadelphia, PA; University of Connecticut (V.B.D.), College of Agriculture and Natural Resources, Storrs, CT; Northwestern University (J.W.G., D.V.), Feinberg School of Medicine, Chicago, IL; Temple University (G.S.), Philadelphia, PA; Rutgers University (P.A.S.B.), School of Environmental and Biological Sciences, New Brunswick, NJ; University of Florida (L.M.B.), Gainesville, FL; Osmic Enterprises, Inc. (L.H.), Cincinnati, OH; and National Institute on Deafness and Other Communication Disorders (H.J.H.), Bethesda, MD.

Go to Neurology.org for full disclosures. Funding information and disclosures deemed relevant by the authors, if any, are provided at the end of the article. 
to select the best methods available for the assessment of gustatory perception in individuals ranging in age from 3 to 85 years, that were also brief (approximately 5 minutes), available at minimal cost, readily administered on a large scale, reliable, and validated.

The team agreed that assessments of bitter, sweet, and salty taste perception should be used. Taste threshold assessments were not feasible because of the time constraints of the NIH Toolbox. Intensity scaling was selected as the methodology for use in adults, whereas a hedonic measure was selected for use in young children (younger than 12 years).

CHOICE OF SCALE A general Labeled Magnitude Scale was selected for all taste-intensity scaling tasks because it has the ability to distinguish a range of taste perception from low or dysfunctional to extremely intense ("supertasters"). ${ }^{4}$ Furthermore, an instructional set has been established that provides brief and consistent training on use of the general Labeled Magnitude Scale, and promotes ease of use in older adults. ${ }^{5,6}$ The team recognized that this scale may not be appropriate for young children.

CHOICE OF TASTE STIMULI FOR USE IN TESTING Bitter taste perception is a key factor in determining the preference for and consumption of leafy vegetables as well as compliance with oral medications, particularly in children. ${ }^{7-9}$ The human diet includes plant products that contain bitter-tasting phytonutrients such as catechins (in tea and red wine) and glucosinolates (in broccoli and cabbage) that have been linked to health benefits. ${ }^{7}$ Individual differences in sensitivity to the bitterness of phytonutrients have been shown to influence both the likability and consumption of plant products such as tea and vegetables. ${ }^{9-11}$ Therefore, bitter taste perception was a suggested area of focus for the NIH Toolbox.

After consideration of a few frequently used bittertasting substances, the taste team selected quinine hydrochloride for inclusion in the NIH Toolbox. Quinine is an alkaloid that is extracted from the bark of the cinchona tree. Quinine is approved by the US Food and Drug Administration as a flavoring agent in tonic water, although there have been a few case studies of quinine hypersensitivity shown as dermatologic symptoms. ${ }^{12}$ Age differences have been observed in both threshold and suprathreshold perception of quinine, making it an appropriate compound for inclusion in longitudinal studies. ${ }^{13}$ The genetics of quinine perception is an area of active research. ${ }^{14}$

Cellular transduction mechanisms differ for each of the 5 basic taste qualities. Receptors for salty and sour perception are thought to activate ion channels, whereas sweet, bitter, and umami perception involve G-protein-coupled receptors. ${ }^{2}$ Because it is possible to have deficits, enhancements, or confusion in perception within an individual taste modality, a thorough gustatory assessment should include representatives from each of the 5 generally accepted taste qualities. For assessment of taste qualities other than bitter, testing with sodium chloride, sucrose, citric acid, and monosodium glutamate are recommended as typical examples of salty, sweet, sour, and umami tastants that would be valuable to include, time permitting.

RATIONALE FOR REGIONAL TESTING Genetic differences in taste-receptor function or expression account for some, but not all, of the individual differences in taste perception. ${ }^{15,16}$ Other differences are likely attributable to the density of papillae on the tongue surface, or environmental factors such as damage to the nerves innervating the oral cavity. ${ }^{15-17}$ For example, the chorda tympani branch of the facial nerve, which innervates the anterior two-thirds of the tongue, is vulnerable to damage because of its anatomical location. Extending along the medial surface of the tympanic membrane in the middle ear, the chorda tympani nerve joins the lingual nerve before passing within the soft tissue of the mandible. This location makes the nerve susceptible to damage from ear infections, middle-ear procedures, jaw

\section{Figure 1 Regional application of tastant to the anterior tongue}

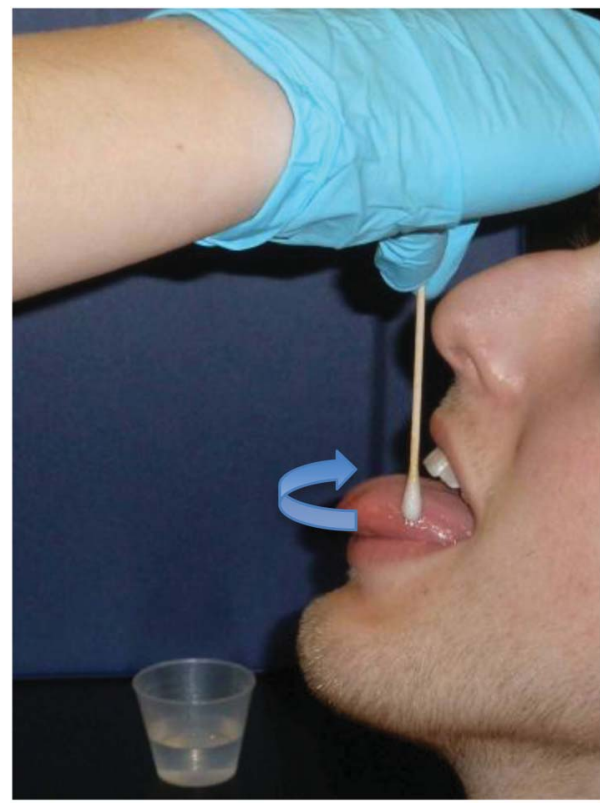

In the Regional Test, the examiner gently applies taste solution to the anterior tongue by moving a cotton swab soaked in taste solution in a slow continuous motion along the front of the tongue. For NIH Toolbox norming, direction of application was always from the left side of the tongue across the tip and finishing on the right side of the tongue. It is also acceptable to reverse the direction of application, moving in a slow continuous motion from the right side, across the tip to the left side. 
injuries, and dental procedures. ${ }^{17}$ Because 3 different cranial nerves (facial, glossopharyngeal, and vagal) innervate taste receptors in the oral cavity, it is difficult to detect localized taste loss by whole-mouth assessment alone. However, damage to the chorda tympani can be detected by isolating taste stimulation to the anterior portion of the tongue (regional application of tastants). Damage to the chorda tympani nerve can lead to the perception of taste phantoms (dysgeusia) and is thought to lead to the perception of oral pain phantoms as well. ${ }^{18}$ Variation in chorda tympani nerve-mediated taste intensity has also been shown to influence vegetable consumption. ${ }^{\text {? }}$

Unilateral reductions of taste on the tip of the tongue can be observed with unilateral sacrifice of the chorda tympani nerve during acoustic neuroma surgery. ${ }^{19}$ However, in the absence of this type of unilateral damage, taste-intensity ratings on the left and right side of the

\section{Figure 2 Sucrose preference test}

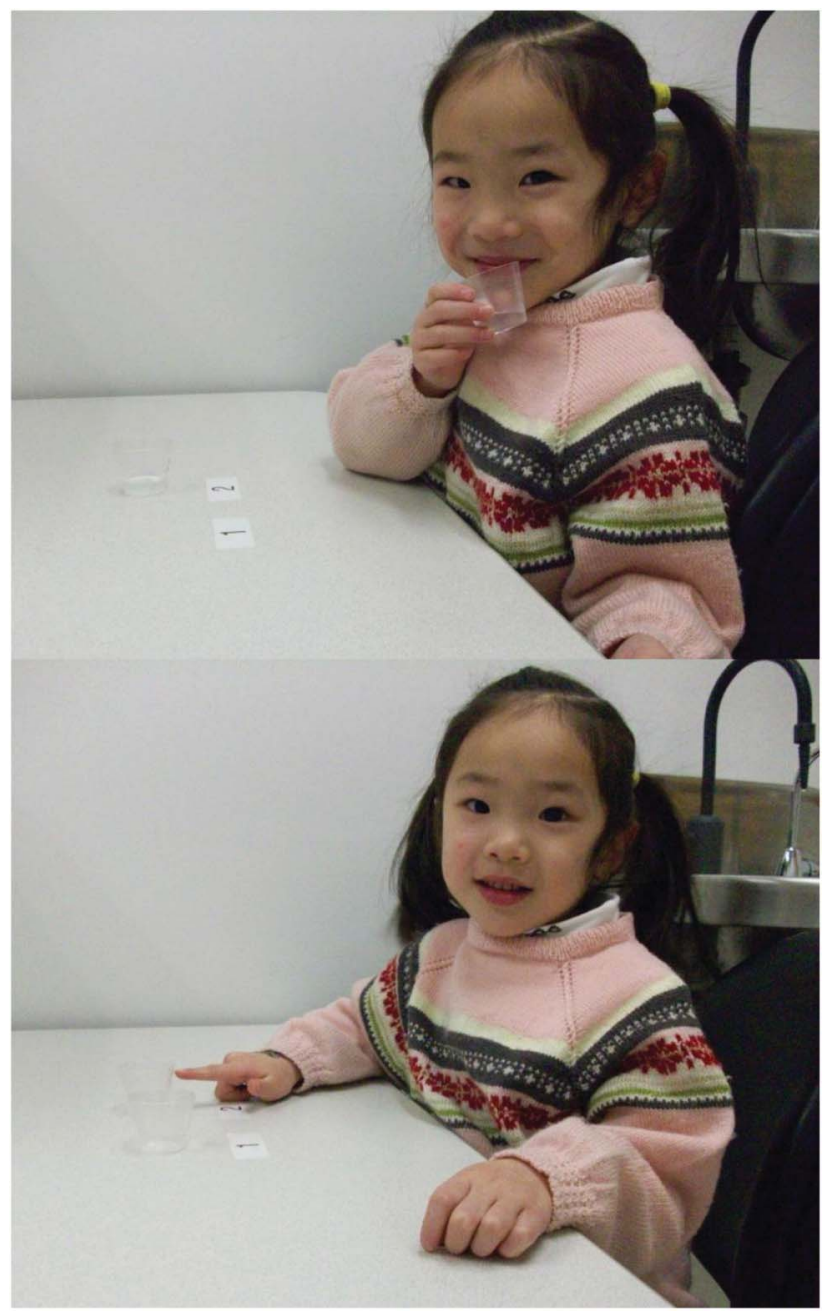

In the sucrose preference test, sucrose solutions are placed on the table in the order they are to be tasted. The first solution to be tasted is placed above the number 1 whereas the second solution tasted is placed above the number 2 . The subject tasted both solutions (top panel) and then pointed to the one she preferred (bottom panel). tongue are highly correlated. ${ }^{20}$ Therefore, because of time constraints, the NIH Toolbox uses a regional test that employs application of taste solution to the entire tongue tip, rather than to each side separately (figure 1).

CHOICE OF A PEDIATRIC MEASURE A forced-choice, paired-comparison, tracking technique for sucrose preference was selected as the NIH Toolbox gustatory measure for young children (figure 2). ${ }^{21,22}$ This method requires participants to taste pairs of sucrose solutions of varying concentrations (from 3\% to 36\%). After tasting each pair of solutions, the participants are asked to point to the solution they prefer. The sucrose preference test continues until the participant chooses the same sucrose concentration twice in a row, relative to both a higher and a lower concentration, excluding the first trial.

This tracking task is brief (approximately 15 minutes) and does not require children to maintain sustained attention or remember previous trials, which could yield spurious age-dependent response differences. The full task includes 2 repetitions or series that alternate solution order. Each series takes 5 to 7 minutes to complete, and requires the presentation of 3 to 9 pairs of solutions. Because the 2-series version exceeds the time limit for gustatory assessment for the NIH Toolbox, we explored whether the method might be shortened to a single series. Existing datasets containing data from 356 children, 169 adolescents, and 424 adults were used for these analyses. Analyses confirmed that a single-series version of the task is sensitive to age effects, with children and adolescents demonstrating higher sucrose preferences than adults. ${ }^{22}$ A single-series version of the assessment was thus selected as the NIH Toolbox gustation measure recommended for young children.

Studies have shown that children have higher preferences for sweet than do adults, with the preference for sweet declining in late adolescence. ${ }^{22}$ In adults, smoking has been associated with decreased sweet preference, whereas a family history of alcoholism is associated with increased sweet preference. ${ }^{23}$ The sucrose preference test is thus recommended as a supplemental measure for older participants, to be administered if time permits.

SUMMARY The NIH Toolbox gustation assessments focus on perceived bitter taste intensity in those 12 to 85 years of age, and on sucrose preference for ages 5 to 85 years of age. These methods employ techniques frequently used in taste psychophysics, which have been modified to meet NIH Toolbox requirements. Validation work indicates that the assessment techniques, as modified for the NIH Toolbox, are adequate to detect individual differences in taste functioning as well as sucrose taste preference. Additional recommended assessments, time permitting, include whole-mouth and regional taste-intensity perception of sour, salty, and umami taste qualities. 


\section{AUTHOR CONTRIBUTIONS}

Dr. Coldwell was the scientific lead for the NIH Toolbox Taste Team, contributed to selection of measures, and also took the lead on drafting the manuscript. Dr. Mennella was a Taste Team member, contributed to selection of measures, and also led validation work on the Sucrose Preference Test. Dr. Duffy was a Taste Team member, contributed to selection of measures, and also led validation work on the Regional Taste Test. Dr. Pelchat was a Taste Team member, contributed to selection of measures, and also led validation work for the Labeled Magnitude Scale in elders. Dr. Griffith was the NIH Toolbox domain manager for the Taste Team and also assisted with data analysis for validation studies. Dr. Smutzer was a Taste Team member, contributed to selection of measures, and led validation work using the Labeled Magnitude Scale primarily in a college student population. Dr. Cowart was a consultant to the NIH for final measure selection on the NIH Toolbox project and contributed critical revision of the manuscript for intellectual content. Dr. Breslin was a Taste Team member, contributed to selection of measures, and contributed critical revision of the manuscript for intellectual content. Dr. Bartoshuk was a Taste Team member, contributed to selection of measures, and contributed critical revision of the manuscript for intellectual content. Dr. Hastings was a Taste Team member and contributed to selection of measures. Dr. Victorson was the original domain manager for the Taste Team and provided guidance to the Taste Team. Dr. Hoffman was a Taste Team member, contributed to selection of measures, provided NIH oversight and guidance to the Taste Team, and contributed critical revision of the manuscript for intellectual content.

\section{ACKNOWLEDGMENT}

The authors thank Gary Beauchamp and Michael O'Mahony for exper assistance with selection of measures.

\section{STUDY FUNDING}

This study is funded in whole or in part with Federal funds from the Blueprint for Neuroscience Research, NIH, under contract no. HHSN-260-2006-00007-C.

\section{DISCLOSURE}

S. Coldwell receives financial support from the University of Washington through the State of Washington and through the Washington Dental Service Endowed Professorship. Additional financial support has been provided by the NIH through grants, contracts, and cooperative agreement numbers DE018768-S1, DE14254, DE016750, TW009071, TW007768, and HHS-N-260-2006-00007-C (NIH Toolbox). Additionally, she serves as a member of the 2011 US Pediatric Formulations Initiative (PFI) Taste, Smell, and Flavor Research in Infants and Children Working Group through NIH. Dr. Coldwell has received research support from GlaxoS mithKline. Dr. Coldwell's husband holds stock in Ascentium Corporation and LifeEdited. J. Mennella is funded, in addition to NIH Toolbox, by NIH grants HD37119, HD072307, and DC011287, and has received investigator-initiated research support from the Pennsylvania Tobacco Settlement Fund, Kikkoman Company, and the Ajinomoto Company. V. Duffy is funded, in addition to the NIH Toolbox, by NIH DC008613, DC00283, NIH USDA Hatch Project CONS00827 funds, USDA SNAPEd, PHS/Centers for Disease Control S8056, Action for Healthy Kids. She has received financial support from Bel Brands, USA to present, as a scientific expert, at the Food and Nutrition Conference of the American Dietetic Association, speaking on the satiating effects on taste and texture. M. Pelchat has received financial support from NIH Toolbox, the Monel Chemical Senses Center, Army Research Office (ARO) W911NF-11-10087, the Ajinomoto Company, Suntory, Ltd., and the Coca-Cola Company. J. Griffith has received financial support from NorthShore University HealthSystem, the Cleveland Clinic Foundation/Teva Neurosciences, Inc. Ironwood Pharmaceuticals, Inc., and Forest Laboratories, Inc., the NIH the Department of Defense (DOD)-United States Army, and the FWO, Belgium. In addition to NIH Toolbox funding, he receives funding from the NIH for other research (grant U01 DK082342). He has also been a paid consultant to Dr. Kathryn Grant of DePaul University, and maintains a clinical psychology practice for which he bills for his services. G. Smutzer received funding from the NIH Toolbox for Neurological and Behavioral Function, contract no. HHS-N-260-2006-00007-C from 2009 to 2011. In addition, he received funds from a phase II SBIR entitled "Cellulose-Based Strips for Human Taste Evaluation" from October 1, 2007 to September 31, 2009 (2R44DC007291). He also received funds from an ARRA supplement for the Phase II SBIR mentioned above from September 1, 2009 to August 31, 2010. He also received funding from the Temple University Undergraduate Research Fund from 2010 to 2012. Dr. Smutzer submitted an invention disclosure to Temple University in June 2012 concerning the use of polycoated paper as a packaging material for edible taste strips, dried foods, and pharmaceuticals. B. Cowart has received financial support from the NIH P50 DC006760 and DC006760-05S2, the Army Research Office (ARO) W911NF-11-1-0087, and the Ajinomoto Company. She has also received institutional support from the Monell Chemical Senses Center, and served as a paid consultant to the NIH Toolbox. P. Breslin receives research support from Rutgers, The State University of New Jersey, and the Monell Chemical Senses Center. He receives support from NIH grants DC02995, DC06760, and DC011393. Dr. Breslin also receives support from the Bill and Melinda Gates Foundation Grand Challenges Explorations Fund. He also receives investigatorinitiated research support from Suntory Business Expert Ltd., and Takasago International Corporation, USA. He is an executive editor at the journal Chemical Senses for which he receives editorial support. L. Bartoshuk has received funding from NIDCD grants DC283 and DC8613. L. Hastings is president and majority shareholder in Osmic Enterprises, Inc., a company that develops and markets tests for the assessment of smell and taste function. Osmic Enterprises received funding from the NIH for other research (grants R44 DC6369 and R44 DC7291). D. Victorson holds stock options in Eli Lilly and Company, received an honoraria for serving on the Steering Committee of the Reeve Neuro-Recovery Network, was funded by NIH contracts HHSN265200423601C and HHS-N-260-2006-00007-C and grants R01HD054569-02NIDRR, 1U01NS056975-01, R01 CA104883, received support from the American Cancer Society (national and Illinois Division) for research in prostate cancer, received institutional support from NorthShore University HealthCare System for research in prostate cancer, received institutional support from the Medical University of South Carolina for sarcoidosis research, and received institutional support from the Northwestern Medical Faculty Foundation for urology research. H. Hoffman is an employee of the extramural program of the NIH. Go to Neurology.org for full disclosures.

\section{EDITOR'S NOTE}

The Sucrose Preference Test was not included in the final NIH Toolbox core batteries. It is available as an experimental measure.

Received June 6, 2012. Accepted in final form October 18, 2012.

\section{REFERENCES}

1. Tepper BJ, White EA, Koeliker Y, et al. Genetic variation in taste sensitivity to 6-n-propylthiouracil and its relationship to taste perception and food selection. Ann NY Acad Sci 2009; 1170:126-139.

2. Yarmolinsky DA, Zuker CS, Ryba NJ. Common sense about taste: from mammals to insects. Cell 2009;139; 234-244.

3. Smith DV, Davis BJ. Neural representation of taste. In: Finger TE, Silver WL, Restrepo D, editors. The Neurobiology of Taste and Smell, 2nd ed. New York: Wiley-Liss; 2000: 353-394.

4. Bartoshuk LM, Duffy VB, Green BG, et al. Valid acrossgroup comparisons with labeled scales: the gLMS versus magnitude matching. Physiol Behav 2004;82:109-114.

5. Rawal S, Bartoshuk LM, Coldwell SE, et al. NIH Toolbox: proposed assessment of taste function and phenotype. Chem Senses 2010;35:A18. Abstract.

6. Pelchat ML, Carfagno G, Coldwell SE. GLMS for ratings of taste intensity by the elderly: ready for the Toolbox? Chem Senses 2010;35:A94. Abstract.

7. Drewnowski A, Gomez-Carneros C. Bitter taste, phytonutrients, and the consumer: a review. Am J Clin Nutr 2000; 72:1424-1435. 
8. Mennella J, Beauchamp GK. Optimizing oral medications for children. Clin Ther 2008;30:2120-2132.

9. Dinehart ME, Hayes JE, Bartoshuk LM, et al. Bitter taste markers explain variability in vegetable sweetness, bitterness, and intake. Physiol Behav 2006;87:304-313.

10. Peyrot des Gachons C, Beauchamp GK, Breslin PA. The genetics of bitterness and pungency detection and its impact on phytonutrient evaluation. Ann NY Acad Sci 2009;1170: 140-144.

11. Gayathri DA, Henderson SA, Drewnowski A. Sensory acceptance of Japanese green tea and soy products is linked to genetic sensitivity to 6-n-propylthiouracil. Nutr Cancer 1997;29:146-151.

12. Kanny G, Flabbée J, Morisset M, Moneret Vautrin DA. Allergy to quinine and tonic water. Eur J Intern Med 2003;14:395-396.

13. Cowart BJ, Yokomukai Y, Beauchamp GK. Bitter taste in aging: compound-specific decline in sensitivity. Physiol Behav 1994;56:1237-1241.

14. Reed DR, Zhu G, Breslin PA, et al. The perception of quinine taste intensity is associated with common genetic variants in a bitter receptor cluster on chromosome 12 . Hum Mol Genet 2010;19:4278-4285.

15. Mennella JA, Pepino MY, Reed DR. Genetic and environmental determinants of bitter perception and sweet preferences in children and adults. Pediatrics 2005;115:e216-e222.
16. Hayes JE, Bartoshuk LM, Kidd J, et al. Supertasting and PROP bitterness depends on more than the TAS2R38 gene. Chem Senses 2008;33:255-265.

17. Bartoshuk LM, Duffy VB, Reed D, et al. Supertasting, earaches and head injury: genetics and pathology alter our taste worlds. Neurosci Biobehav Rev 1996;20: 79-87.

18. Bartoshuk LM, Snyder DJ, Grushka M, et al. Taste damage: previously unsuspected consequences. Chem Senses 2005;30: i218-i219.

19. Kveton JF, Bartoshuk LM. The effect of unilateral chorda tympani damage on taste. Laryngoscope 1994;104:25-29.

20. Coldwell SE, Drangsholt MT, Huggins KH, et al. Reliability of a brief spatial test for assessment of gustatory function. Chem Senses 2011;36:A24. Abstract.

21. Beauchamp GK, Cowart BJ. Preference for high salt concentrations among children. Dev Psychol 1990;26: 539-545.

22. Mennella JA, Lukasewycz LD, Griffith JW, et al. Evaluation of the Monell forced-choice, paired-comparison tracking procedure for determining sweet taste preference across the lifespan. Chem Senses 2011;36:345-355.

23. Pepino MY, Mennella JA. Effects of cigarette smoking and family history of alcoholism on sweet taste perception and food cravings in women. Alcohol Clin Exp Res 2007;31: 1891-1899. 


\section{Neurology}

Gustation assessment using the NIH Toolbox

Susan E. Coldwell, Julie A. Mennella, Valerie B. Duffy, et al.

Neurology 2013;80;S20-S24

DOI 10.1212/WNL.0b013e3182872e38

This information is current as of March 11, 2013

\section{Updated Information \&} Services

\section{References}

Citations

Subspecialty Collections

Permissions \& Licensing

Reprints including high resolution figures, can be found at: http://n.neurology.org/content/80/11_Supplement_3/S20.full

This article cites 22 articles, 1 of which you can access for free at: http://n.neurology.org/content/80/11_Supplement_3/S20.full\#ref-list-1

This article has been cited by 2 HighWire-hosted articles: http://n.neurology.org/content/80/11_Supplement_3/S20.full\#\#otherarti cles

This article, along with others on similar topics, appears in the following collection(s):

All Clinical Neurology

http://n.neurology.org/cgi/collection/all_clinical_neurology

All Medical/Systemic disease

http://n.neurology.org/cgi/collection/all_medical_systemic_disease All Pediatric

http://n.neurology.org/cgi/collection/all_pediatric

Information about reproducing this article in parts (figures,tables) or in its entirety can be found online at:

http://www.neurology.org/about/about_the_journal\#permissions

Information about ordering reprints can be found online:

http://n.neurology.org/subscribers/advertise

Neurology ${ }^{\circledR}$ is the official journal of the American Academy of Neurology. Published continuously since 1951 , it is now a weekly with 48 issues per year. Copyright (C) 2013 American Academy of Neurology. All rights reserved. Print ISSN: 0028-3878. Online ISSN: 1526-632X.

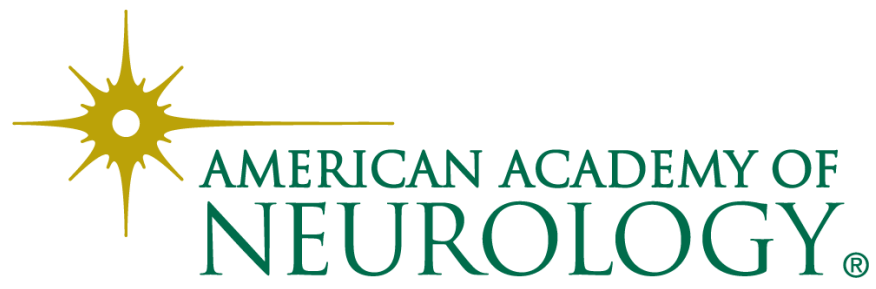

